\title{
Molecular Cloning and Nucleotide Sequence of Complementary DNAs Encoding Human Short Chain Acyl-Coenzyme A Dehydrogenase and the Study of the Molecular Basis of Human Short Chain Acyl-Coenzyme A Dehydrogenase Deficiency
}

\author{
Etsuo Naito, Hisashi Ozasa, Yasuyuki Ikeda, and Kay Tanaka \\ Department of Human Genetics, Yale University School of Medicine, New Haven, Connecticut 06510
}

\begin{abstract}
Complementary DNAs encoding the precursor of human placental short chain acyl-coenzyme A (CoA) dehydrogenase (SCAD) (EC 1.3.99.2) were cloned and sequenced. The cDNA inserts in these clones were 1,852 bases in length combined, and encoded the entire 412-amino acid precursor SCAD (mol wt 44,303). This sequence included the 24 -amino acid leader peptide moiety (mol wt 2,576 ) and 388 amino acids corresponding to the mature protein (mol wt 41,727). The comparison of SCAD and medium chain acyl-CoA dehydrogenase sequences revealed a high degree of homology, suggesting that these enzymes evolved from a common ancestral gene and belong to a gene family. We also studied mutant human SCAD in cultured skin fibroblasts from three patients with hereditary SCAD deficiency. Labeling fibroblast cultures with $\left[{ }^{35} \mathrm{~S}\right]-$ methionine followed by immunoprecipitation with anti-SCAD antibody revealed that a normal size variant $S C A D$ protein was synthesized. In all of the three SCAD-deficient cell lines, the size of variant SCAD mRNA as determined by Northern blotting using one of the normal SCAD cDNA as a probe was also normal, and no difference was observed on Southern blots in the restriction patterns of mutant genomic DNA using EcoRI, TaqI, HincII, and BamHI. These results suggest that the defects in SCAD in these cell lines are caused by a point mutation.
\end{abstract}

\section{Introduction}

Short chain acyl-coenzyme A dehydrogenase (SCAD) ${ }^{1}$ (EC 1.3.99.2) is one of five homologous acyl-coenzyme A (CoA) dehydrogenases. It catalyzes the first reaction in the $\beta$-oxida-

Dr. Ozasa's present address is Tokyo Women's Medical College, Tokyo, Japan; Dr. Ikeda's present address is National Cardiovascular Center Research Institute, Fujishiro-dai, Suita 565, Japan.

Address reprint requests to Dr. Tanaka.

Received for publication 29 September 1988 and in revised form 28 December 1988

1. Abbreviations used in this paper: CoA, coenzyme A; ETF, electron transfer flavoprotein; IVD, isovaleryl-CoA dehydrogenase; LCAD, long chain acyl-CoA dehydrogenase; MCAD, medium chain acyl-CoA dehydrogenase; 2-meBCAD, 2-methyl-branched chain acyl-CoA dehydrogenase; nt, nucleotide; $p$, precursor; RFLP, restriction fragment length polymorphism; SCAD, short chain acyl-CoA dehydrogenase.

J. Clin. Invest.

(C) The American Society for Clinical Investigation, Inc.

0021-9738/89/05/1605/09 \$2.00

Volume 83, May 1989, 1605-1613 tion of short chain acyl-CoAs. Other enzymes in this group are medium chain acyl-CoA (MCAD), long chain acyl-CoA (LCAD), isovaleryl-CoA (IVD) and 2-methyl-branched chain acyl-CoA dehydrogenases (2-meBCAD) (1-3). Each of the acyl-CoA dehydrogenases is a homotetrameric mitochondrial flavoprotein with a subunit molecular size of $40-45 \mathrm{kD}$, and containing $1 \mathrm{~mol}$ of flavin adenine dinucleotide (FAD) per subunit (1-3). All five enzymes are synthesized in the cytosol as a precursor (p) that is $2-4 \mathrm{kD}$ larger than the mature counterpart. The precursor contains a short leader peptide that is attached to the amino terminus of the mature protein (4). The precursor is imported into mitochondria by an energy-dependent mechanism, and is processed by proteolytic cleavage of the leader peptide (4). In rat, the molecular sizes of mature SCAD and pSCAD, and that of the leader peptide were estimated to be 41,45 , and $4 \mathrm{kD}$, respectively $(1,4)$. The molecular size of purified human SCAD is also $41 \mathrm{kD}(5)$, but the sizes of the human pSCAD and its leader peptide are currently unknown.

All acyl-CoA dehydrogenases require electron transfer flavoprotein (ETF) as an electron acceptor, and share identical reaction mechanisms (6). However, they distinctly differ from each other in regard to the length and configuration of the hydrocarbon chain of the respective substrates. Their close functional and structural similarities suggest that the five acylCoA dehydrogenases may have evolved from a single ancestral gene and diverged in the course of evolution. For this reason, we have previously proposed that the five acyl-CoA dehydrogenases belong to a gene family (7).

Hereditary SCAD deficiency has recently been reported by two groups of investigators in three young infants. The main clinical features in two of them were metabolic acidosis and ethylmalonic aciduria $(8,9)$, with one patient dying in the neonatal period due to severe metabolic acidosis and hyperammonemia. The third patient had a history of progressive skeletal muscle weakness, developmental delay, and muscle carnitine deficiency. Butyryl-C $\ominus \mathrm{A}$ dehydrogenating activity in the cultured fibroblasts from all three infants, assayed in the presence of anti-medium chain acyl-CoA dehydrogenase antibody, was found to be $<11 \%$ of controls, indicating a specific SCAD deficiency $(8,9)$.

As the first step in the study of the molecular basis of hereditary SCAD deficiency, we have cloned and sequenced cDNAs encoding the entire human pSCAD. Furthermore, we studied mutant human SCAD in cultured skin fibroblasts from three patients with hereditary SCAD deficiency at the protein level using labeling with $\left[{ }^{35} \mathrm{~S}\right]$ methionine and immunoprecipitation, and at the RNA and DNA levels by Northern and Southern blots, respectively, using one of the isolated SCAD cDNA clones as a probe. 


\section{Methods}

Materials. $\left.\mathrm{L}-{ }^{35} \mathrm{~S}\right]$ Methionine $(1,400 \mathrm{Ci} / \mathrm{mmol})$ was purchased from Amersham Corp. (Arlington Heights, IL). Inactivated Staphylococcus aureus cells and ${ }^{14} \mathrm{C}$-labeled protein standard were from Bethesda Research Laboratories (Gaithersburg, MD). Rhodamine 6G was procured from Eastman Kodak Co. (Rochester, NY), and cell culture materials were from Gibco (Grand Island, NY). All restriction enzymes were from Promega Biotec (Madison, WI). The sources of some enzymes and reaction kits are indicated directly after the respective names in the text. Rat liver and human placenta cDNA libraries, constructed in a $\lambda$ gt 11 expression vector, were purchased from Clontech Laboratories (Palo Alto, CA)

Source of cell lines. The sources of SCAD-deficient cell lines have been previously reported $(8,9)$. Normal cell lines were obtained from the NIGMS Human Genetic Mutant Cell Repository (Camden, NJ).

Purification of human and rat SCAD, and preparation of antibody against rat SCAD. Purification of rat and human SCAD to homogeneity and the purity of the respective preparations used in this study were previously reported (references 1 and 5 , respectively). Both preparations were of the highest purity. Both of them were completely free of contamination by other four acyl-CoA dehydrogenases as ascertained by the following criteria. In the purification process, activities for five acyl-CoAs with varying chain length and configuration were monitored in sequential fractions from column chromatography at each step, ensuring the separation from other acyl-CoA dehydrogenases (1). Each of the rat and human SCAD preparations was a single band on SDS-PAGE, which is capable of clearly separating SCAD from other acyl-CoA dehydrogenases, including MCAD, LCAD, IVD, and 2meBCAD owing to the differences in molecular size $(1,5)$. Furthermore, it was not inactivated by anti-MCAD, anti-LCAD, and antiIVD antibodies in immunotitration, while it was completely inactivated by anti-SCAD antibody. In Ouchterlony double immunodiffusion, the rat SCAD preparation produced a single precipitin line with anti-SCAD antibody, but no precipitin line was formed when reacted with antibodies raised against MCAD, LCAD, or IVD. The purity of human SCAD was of similar degree as tested by similar methods except for the double immunodiffusion method (5). Anti-rat SCAD antibody was raised in rabbit and purified as previously reported (1). The antibody was monospecific, and did not cross-react with any other rat acyl-CoA dehydrogenases (1). However, it cross-reacted with human SCAD (10).

Tryptic digestion, isolation of tryptic peptides, and amino acid sequencing. A pure rat SCAD preparation $(0.5 \mathrm{mg})$ was first S-carboxymethylated with iodoacetic acid and then digested with trypsin. The resulting peptides were separated by reverse-phase HPLC on a Vydac C18 column (4.6 mm $\times 25 \mathrm{~cm}$ Separations Group, Hesperia, CA) using a $0.05 \%$ trifluoroacetic acid and a $0-80 \%$ acetonitrile gradient. Edman degradation was performed in a gas-phase sequencer, model 470 (Applied Biosystems, Inc., Foster City, CA) equipped with a 120A in-line PTH analyzer. The amino-terminal sequence of human SCAD (5) was likewise determined using the undigested enzyme.

Screening of the cDNA library. First, the IgG fraction from monospecific, polyclonal anti-rat SCAD antiserum (1) was absorbed with Escherichia coli strain Y 1090 lysate to remove materials which crossreacted with $E$. coli proteins. The rat liver cDNA library was screened using the preabsorbed anti-rat SCAD antibody according to the method of Young and Davis (11), except for the detection of $\beta$-galactosidase/SCAD fusion proteins. We used goat anti-rabbit IgG/alkaline phosphatase conjugate (Bio-Rad Laboratories, Richmond, CA) as a secondary antibody for detection according to the supplier's protocol. $5 \%$ nonfat dry milk (Carnation, Los Angeles, CA) was utilized in place of bovine serum albumin to reduce nonspecific protein binding to nitrocellulose membrane.

The human placenta cDNA library was screened by hybridization (12) using as a probe one of the rat SCAD cDNA clones (RS-11), which was radiolabeled with $\left[{ }^{32} \mathrm{P}\right] \mathrm{dCTP}$ by the random primer DNA-labeling method (13).
Subcloning of $c D N A$. After secondary and tertiary screening, positive cDNA clones were isolated and digested with appropriate restriction enzymes, and subcloned into the pGEM-blue transcription vector (Promega Biotec). The newly constructed plasmid was used to transform E. coli, strain XL1-Blue (Stratagene, La Jolla, CA).

DNA sequencing. DNA sequencing was performed directly on cDNA inserts in pGEM-blue plasmid by the dideoxy-sequencing method (14) using T7 or SP6 oligonucleotide as primer (Promega Biotec) and ${ }^{35} \mathrm{~S}$-labeled nucleoside thiotriphosphates (Amersham Corp.) and the Sequenase kit (United States Biochemical Corporation, Cleveland, $\mathrm{OH}$ ) as substrates. In some experiments, dGTP was substituted with dITP in order to eliminate ambiguity due to band compression in GC rich regions.

Sequence homology analysis. Sequence homology analysis was carried out using the computer programs of the University of Wisconsin Genetics Computer Group, including Bestfit, Compare, and Gap.

Labeling with ${ }^{35}$ S $]$ methionine, immunoprecipitation, and electrophoretic analysis of variant SCAD in cultured fibloblasts. Labeling of cultured fibroblasts with $\left.{ }^{35} \mathrm{~S}\right]$ methionine, immunoprecipitation and electrophoretic analysis of labeled variant SCAD were carried out according to the method of Ikeda et al. (15).

In vitro transcription/translation of $c D N A$. The cDNA insert of a SCAD cDNA clone (HS-1) was isolated after digestion with EcoRI, and subcloned into the pGEM-blue transcription vector. In vitro transcription of the cDNA was carried out using SP6 RNA polymerase (Boehringer Mannheim Biochemicals, Indianapolis, IN), according to the protocol suggested by the manufacturer. In vitro translation was carried out using the rabbit reticulocyte lysate translation system (Bethesda Research Laboratories) with a $30-\mu$ l final volume as previously reported (16). $3 \mu$ l of the translation mixture was directly analyzed by SDS-PAGE as described by Laemmli (17), and $27 \mu \mathrm{l}$ was reacted with monospecific anti-SCAD antibody and inactivated Staphylococcus aureus cells, and the resulting immunoprecipitates were analyzed by electrophoresis.

Northern blot. Total RNA was prepared from human and rat livers, and cultured human skin fibroblasts using the guanidinium isothiocyanate (18). $20 \mu \mathrm{g}$ of RNA was denatured in formaldehyde/formamide and electrophoresed in a formaldehyde-containing $1.0 \%$ agarose gel (12). RNA was transferred to a sheet of Hybond-N membrane (Amersham Corp.) by capillary blotting. Prehybridization and hybridization were performed according to the manufacturer's protocol. The HS-1 insert was used as a probe in hybridization.

Southern blot analysis of restriction fragments. Genomic DNA was prepared from normal and SCAD-deficient human cultured fibroblasts with the guanidinium isocyanate method (18). $10 \mu \mathrm{g}$ each of genomic DNA was digested with HincII, BamHI, TaqI, or EcoRI. The resulting fragments were analyzed on a $1.0 \%$ agarose gel and transferred onto a sheet of Hybond-N membrane (Amersham Corp.) according to the manufacturer's protocol. The DNA in the filter was then hybridized with ${ }^{32} \mathrm{P}$-labeled HS-1 insert.

\section{Results}

Isolation of rat liver SCAD cDNA clones. Since the cross-reactivity of the anti-rat SCAD antibody to human SCAD was relatively weak, we first isolated rat SCAD cDNAs and used one of them as a probe in the cloning of human SCAD cDNA. A half-million plaques from a rat liver cDNA library in $\lambda g t 11$ expression vector (Clontech Laboratories) were screened using a monospecific, polyclonal, anti-rat SCAD antibody as a probe. Five positive clones were isolated. One of them (RS-11) produced a fusion protein with a molecular size of $136 \mathrm{kD}$ that contained a $20-\mathrm{kD}$ portion of rat SCAD. The DNA sequence of the 1,041-bp insert of this clone contained three portions, whose predicted amino acid sequence perfectly matched the amino acid sequences of three tryptic peptides of rat SCAD 
(total of 57 amino acid residues), confirming that this clone encoded rat SCAD. Four other positive clones were also found to code for rat SCAD, but the inserts from all of them were shorter than $1.0 \mathrm{~kb}$ and covered only the $3^{\prime}$ half of the SCAD sequence.

Isolation of $c D N A$ s encoding human placenta SCAD. Using one of the isolated rat SCAD cDNAs as a probe (RS-11), $\sim 250,000$ recombinant phages from the human placental cDNA library in $\lambda$ gt 11 expression vector (Clontech Laboratories) were screened. 26 positive signals were identified in the primary screening. After the secondary and tertiary screening, 13 putative human SCAD cDNA clones were isolated. The size of the cDNA inserts in these 13 clones ranged from 1,200 to $1,800 \mathrm{bp}$. The restriction patterns of the isolated human SCAD CDNA clones indicated that two of them (HS-1 and HS-12) extended further at both ends than any of the other clones. These two clones were both $\sim 1.8 \mathrm{~kb}$ in length. HS- 12 was shifted 30-40 bases down stream, when compared to HS-1. The restriction maps are shown in Fig. 1.

Synthesis of normal SCAD in cultured human fibroblasts. To characterize normal human SCAD in cultured fibroblasts, fibroblasts were grown in the presence of $\left[{ }^{35} \mathrm{~S}\right]$ methionine and cell lysates were immunoprecipitated using anti-rat SCAD antibody and inactivated Staphylococcus aureus cells. When the precipitates were analyzed by SDS-PAGE (Fig. $2 A$ ), a major radioactive band with a molecular size of $41 \mathrm{kD}$ was observed. This radioactive band was not detected when an excessive amount $(7 \mu \mathrm{g})$ of pure rat SCAD was added before immunoprecipitated (competion experiment) (Fig. $2 A$, lane 2 ), or when unimmunized rabbit serum was used for immunoprecipitation (Fig. $2 A$, lane 3 ), confirming that this band is indeed SCAD.

When $\left[{ }^{35} \mathrm{~S}\right]$ methionine labeling of the cells was done in the presence of rhodamine $6 \mathrm{G}$, followed by immunoprecipitation using anti-rat SCAD antibody, the $41-\mathrm{kD}$ band greatly decreased and a new radioactive band with an $M_{\mathrm{r}}$ of $44 \mathrm{kD}$ appeared (Fig. $2 B$, lane 3). Rhodamine $6 \mathrm{G}$ is an inhibitor of mitochondrial energy metabolism known to inhibit the import of pSCAD into mitochondria (4). Therefore, in the presence of rhodamine $6 \mathrm{G}$, pSCAD cannot be converted to SCAD. Im- munoprecipitation of this $44-\mathrm{kD}$ species could also be blocked by the addition of excess pure rat SCAD (Fig. $2 B$, lane 4 ), indicating that the 44-kD band was pSCAD.

In vitro transcription/translation of human SCAD cDNA. The cDNA insert of HS- 1 was transcribed and the resulting mRNA was translated. When the translation products were directly analyzed by SDS-PAGE, two major radioactive bands with 46 and $44 \mathrm{kD}$ were detected (Fig. 3, lane 2). In addition, several minor bands with smaller molecular sizes were also detectable. The 46-kD band was also detected when transcription/translation was done without addition of mRNA (lane 1), indicating that this band was an artifact, probably a methionine adduct (16). When the translation products were analyzed after immunoprecipitation with anti-rat SCAD antibody, the $44-\mathrm{kD}$ band and a few minor bands with smaller sizes were detected, but the $46-\mathrm{kD}$ band was not (lane 3 ). The size of the 44-kD band was identical to that of human pSCAD, synthesized in the cultured fibroblasts (Fig. $2 B$, lane 3). This result confirms that the HS- 1 insert encodes the entire human pSCAD. The minor shorter polypeptides probably represent products derived from translation initiated at internal methionine codons.

Nucleotide and amino acid sequences of human SCAD. The nucleotide and deduced amino acid sequences of human SCAD cDNA are shown in Fig. 4. In order to confirm that HS- 1 and HS- 12 encodes human pSCAD and to ascertain the reading frame, the amino acid sequence deduced from the nucleotide sequence was compared to the amino terminal sequence of human SCAD (5) and the amino-terminal and three tryptic peptide sequences of rat SCAD (1). 15 amino acid residues from Leu- 25 of the deduced amino acid sequence perfectly matched the amino-terminal sequence of human SCAD, with the exception of two residues (Fig. 4). First, the amino terminal residue could not be identified, presumably owing to the masking of the amino group. However, since the second residue was His, followed by $\mathrm{Thr}$ as were in the deduced sequence, Leu-25 was identified as the amino terminus of human SCAD. In the case of rat SCAD, Leu- 25 was unequivocally identified as the amino terminus. Secondly, the 13 th residue could not be identified in the peptide analysis. The de-

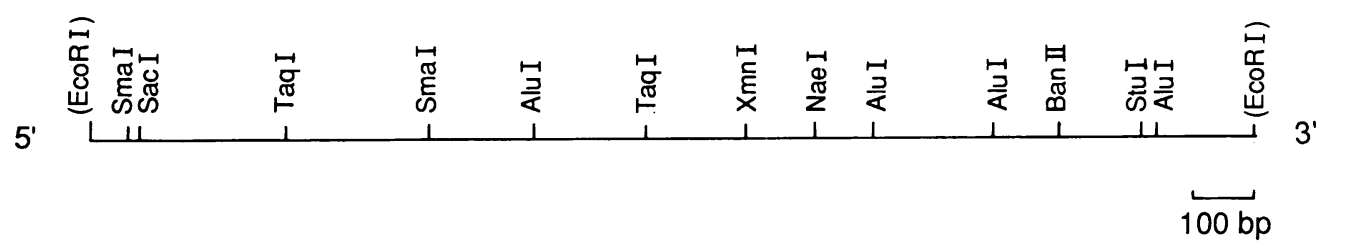

HS-1

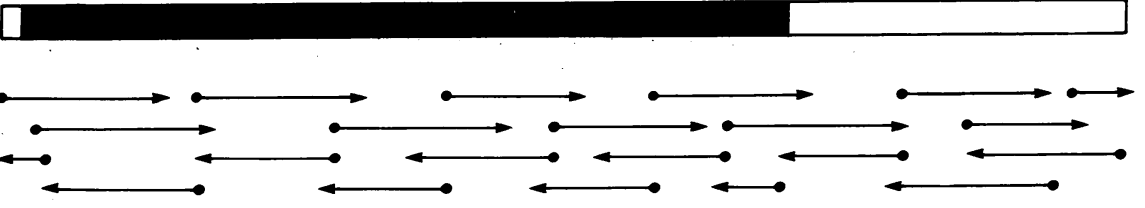

Figure 1. Partial restriction map of human SCAD cDNA clones and sequencing strategy. The sections of the cDNA inserts that are shown with solid and open bars indicate the coding and noncoding regions, respectively. The cDNA inserts were digested with the indicated restriction enzymes. The fragments were subcloned into pGEM-blue and sequenced using $\mathrm{T} 7$ and SP6 promoter primers. The arrows indicate the direction and extent of DNA sequenced from each fragment.

HS-12

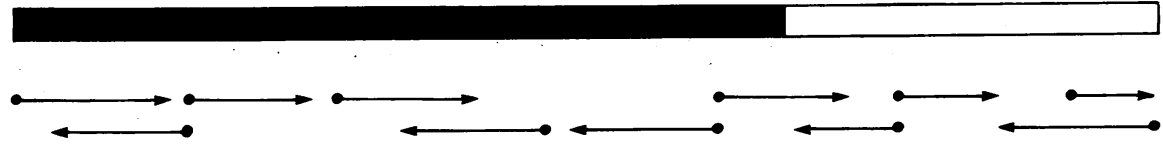


A

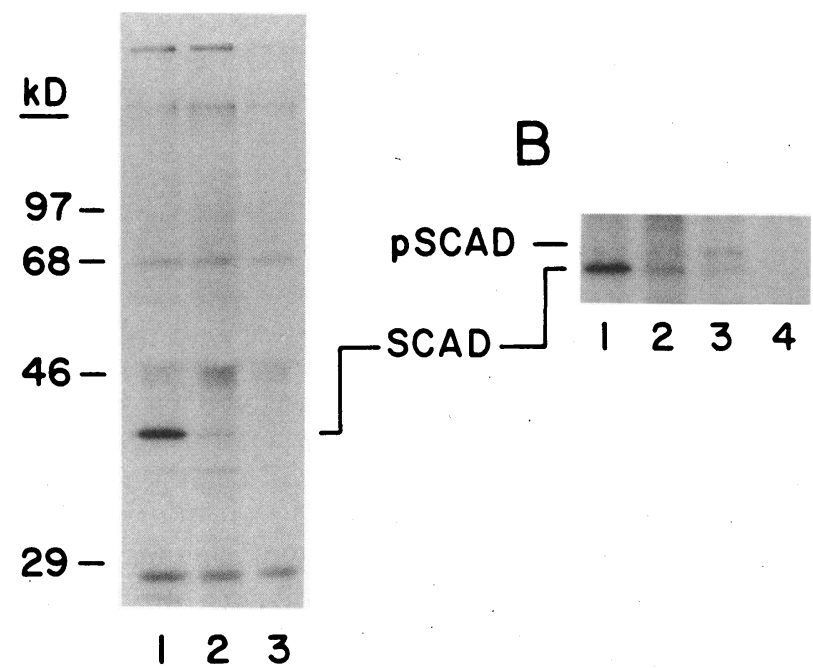

Figure 2. Slab SDS/PAGE of the $\left[{ }^{35}\right.$ S $]$ methionine-labeled SCAD synthesized by normal cultured human fibroblasts. $(A)$ A normal fibroblast cell line (GM08333) was used. The confluent monolayers in 6-cm dishes were labeled and the cell extracts were immunoprecipitated using anti-rat SCAD antibody (10 $\mu \mathrm{l}$ each), and the immunoprecipitates were analyzed on $10 \%$ SDS-PAGE as previously reported (15). Lane 1 , normal cells were labeled with $\left[{ }^{35}\right.$ S $]$ methionine, immunoprecipitated using anti-rat SCAD antibody, and electrophoresed; lane 2, the same normal cells were labeled with $\left[{ }^{35} \mathrm{~S}\right]-$ methionine, and $7 \mu \mathrm{g}$ of unlabeled pure SCAD was added to the cell extract, immunoprecipitated (competition experiment), and then electrophoresed; and lane 3, a control in which anti-SCAD antibody was replaced with nonimmune rabbit serum. (B) A normal fibroblast cell line (GM08333) was used. Experimental conditions for lanes 1 and 2 are the same as in lanes 1 and 2 in $A$. Cell labeling was done in the absence of rhodamine $6 \mathrm{G}$, and immunoprecipitated without (lane 1) and after addition of pure rat SCAD (lane 2). Lanes 3 and 4 were labeled with $\left[{ }^{35} \mathrm{~S}\right] \mathrm{methionine}$ in the presence of $2.1 \mu \mathrm{M}$ rhodamine $6 \mathrm{G}$, and immunoprecipitated without (lane 3 ) and after addition of pure rat SCAD (lane 4).

duced amino acid sequence also well matches the amino-terminal sequence including Leu- 25 and the sequences of three tryptic peptides of the purified rat SCAD (total of 80 amino acid residues). The three discordant amino acid residues in the

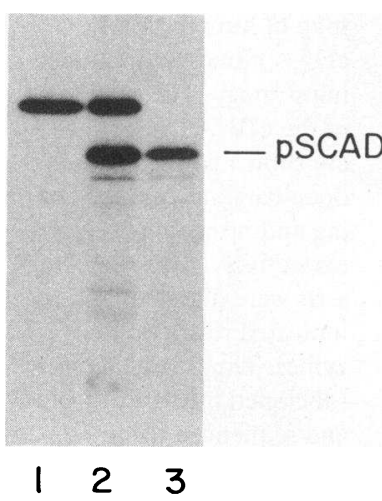

Figure 3. In vitro transcription and translation of SCAD cDNA. The HS-1 insert was subcloned into pGEM-blue transcription vector. In vitro transcription was carried out using SP6 RNA polymerase. In vitro translation was carried out using the rabbit reticulocyte lysate system. Lane 1 , translation with no added mRNA; lane 2 , translation products of mRNA transcribed from HS-1 cDNA (the peptides were directly electrophoresed); lane 3, translation products of mRNA tran-

scribed from HS-1 cDNA. Peptides were electrophoresed after immunoprecipitation with anti-SCAD antibody. The position of human PSCAD is indicated on the right. comparison to rat SCAD tryptic peptides are presumably due to species divergence. The substitutions in the rat sequence are indicated in Fig. 4, under their human counterpart. These comparisons to the amino terminal and tryptic peptide sequences of human and rat SCAD conclusively identify the cDNAs as encoding human pSCAD, and indicate that Leu-25 is the amino terminus of the mature human SCAD.

ATG at 1 was identified as the translation initiation codon for the following reasons. First, the size of the peptide initiated from this codon in the in vitro transcription/translation (Fig. 3) was identical to that of the pSCAD synthesized in human fibroblasts (Fig. 2). Secondly, the 23-amino acid region between Met-1 and Leu-25 contains five Arg residues and no acidic residues, rendering a positive charge. The high abundance of basic amino acids in the absence of acidic residues is a characteristic feature commonly observed in the leader peptide of nuclear encoded mitochondrial enzymes (19). The possibility that there is another ATG upstream, which may serve as the initiation codon, is unlikely, since there is no methionine in the region from -1 to -32 . If there was another ATG codon further upstream, the size of the leader peptide, that is synthesized from it, would considerably exceeds the size of the real leader peptide that was demonstrated in the cell labeling experiment as shown in Fig. 2. Also, the region upstream of the ATG at 1, when translated, would add a 10-amino acid stretch containing an aspartate residue and no basic residues. Unlike the 24-amino acid region starting from Met-1, this hypothetical 10-amino acid region does not conform with the known features of the leader peptides of the nuclear coded mitochondrial enzymes (19).

The cDNA insert of HS-1 contained a 32-base segment of 5 '-noncoding region and the entire coding region. The coding region of human SCAD cDNA contains $1,236 \mathrm{bp}$, which can be translated into a 412-amino acid protein. The HS-1 insert also contained a portion of the 3'-noncoding region, but did not contain the poly(A) tail. In contrast, HS-12 started from the $G$ of the initiation codon, missing an $A$ and $T$, but contained a small portion of the poly(A) tail. Thus, HS- 1 and HS-12, when combined, covered nearly the entire full-length of human SCAD cDNA. The polyadenylation signal (AATAAA) is located at position 1,778 , and the poly(A) tail of 23 adenine residues starts $15 \mathrm{nt}$ downstream from this signal. This spatial arrangement is in good agreement with the consensus sequence for polyadenylation signal (20).

The calculated molecular sizes of the human pSCAD was 44,303. The sizes of the mature human SCAD and the leader peptide moiety were 41,727 and 2,576 , respectively. The overall predicted amino acid composition of the human sequence agrees well with values obtained using purified human SCAD, with only a few minor differences (Table I) (5).

Sequence homology between human short chain and medium chain acyl-CoA dehydrogenases. The amino acid sequences of human pSCAD and human pMCAD (21) are compared in Fig. 5. Human pSCAD and pMCAD consist of 412 and 421 amino acid residues, respectively, including 24 and 25 amino acid residues in the respective leader peptides. The amino terminus of mature human MCAD has not been identified, but it is presumably Lys- 26 by analogy to that of rat MCAD (22). Thus, the number of the amino acid residues in the mature SCAD and MCAD are 388 and 396, respectively. Human pSCAD and pMCAD share $36.7 \%$ of identical residues. When conservative substitutions are included, the ho- 


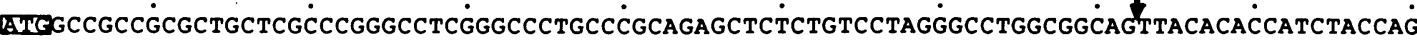

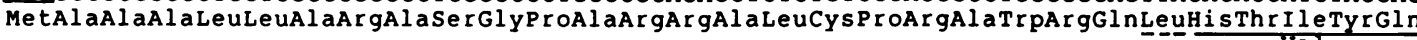
TCTGTGGAACTGCCCGAGACACACCAGATGTTGCTCCAGÁCATGCCGGGACTTTGCCGAGAAGGAGTTGTTTCCCATTGCAGCCCAGGTG SerValGluLeuProGluThrhisGlnMetLeuLeuGlnThrCysArgAspPheAlagluLysGluLeupheProI eAlaAlaGlnVal GATAAGAACATCTI AspLysGluH i sLeuPheProAlaAlaGlnVal Lys LysMe tGlyGlyLeuGlyLeuLeuAlaMe tAspValProGluGluLeuGlyGly GCTGGCCTCGATTACCTGGCंCTACGCCATCंGCCATGGAGGAGATCAGCCGंTGGCTGCGCC̈TCCACCGGAGTCATCATGAGTGTCAACAAC AlaGlyLeuAspTyrLeuAlaTyrAlaI leAlaMe tGlugluI leSerArgGlyCysAlaSerThrGlyValileMetSerValAsnAsn TCTCTCTACCTGGGGCCCATCTTGAAGTTTGGCTCCAAGGAGCAGAAGCAGGCGTGGGTCACGCCTTTCACCAGTGGTGÁCAAAATTGGC

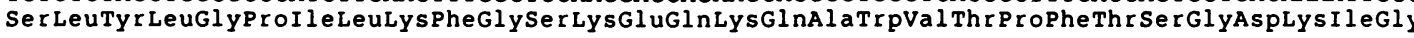
TGCTTTGCCCंTCAGCGAACCAGGGAACGGCAGTGATGCAGGAGCTGCGTCCACCACCGCCंCGGGCGAGG̈GGACTCATGGGTTCTGAAT

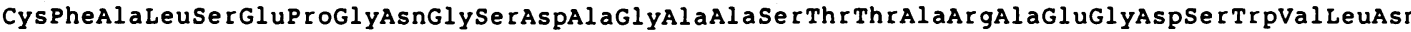
GGAACCAAAĞCCTGGATCAC̈CAATGCCTGGGAGGCTTCGG̈CTGCCGTGGTCTT'TGCCAGCACGGACAGAGCCCTGCAAAACAAGGGCATC

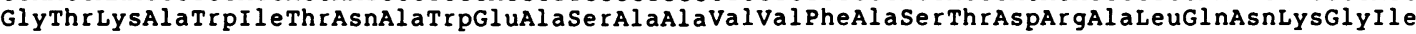

作 AGTGCCTTCCTGGTCCCCATGCCAACGCCTGGGCTCACGTTGGGGAAGAAAGAAGACAAGCTGGGCATCCGGGGCTCATCCACGGCCAA SerAl a Phe LeuVal ProMe tProThrProGlyLeuThrLeuGlyLysLysGluAspLysLeuGly I leArgGlySerSerThrAlaAsn

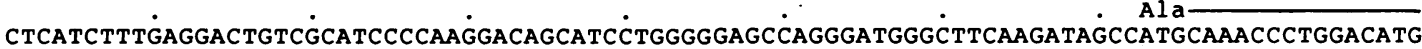
LeuI lePheGluAspCysargI le ProLysAspSerI leLeuGlyGluProglyMetGlyPhelysi leAlaMetGlnThrLeuAspMet GGCCGCATCGGCATCGCCTCCCAGGCCCTGGGCATTGCCCAGACCGCCCTCGATTGTGCTGTGAACTACGCTGAGAATCGCATGGCCTTC GlyArgI leGlyI leAlaserGlnAlaLeuGlyI leAlaGlnThrAl a LeuAspCysAlavalAsnTyrAlagluAsnArgMe tAlaphe GGGGCGCCCCंTCACCAAGCTCCAGGTCATCCAGTTCAAGTTGGCAGACATGGCCCTGGCCंTGGAGAGTGCCCGGCTGCTGACCTGGCGC GlyAlaProLeuThrLysLeuGlnVal I leGlnPheLysLeuAlaAspMe tAl aLeuAlaLeugluSerAlaArgLeuLeuThrTrpArg GCTGCCATGCTGAAGGATAACAAGAAGCCTTTCATCAAGGAGGCAGCCATGGCCAAGCTGGCCGCCTCGGAGGCCGCGACCGCCATCAGC

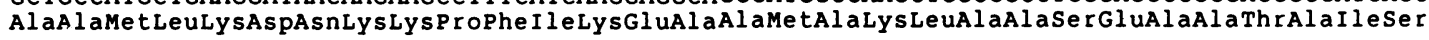
CACCAGGCCÁTCCAGATCCTGGGCGGCATGGGCTACGTGÄCAGAGATGCC̈GGCAGAGCGGCACTACCGCGACGCCCGCATCACTGAGATC

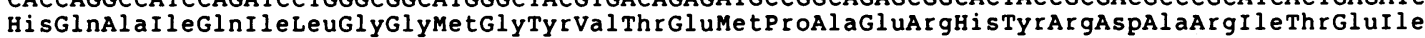
TACGAGGGCACCAGCGAAATCCAGCGGCTGGTGATCGCCGGGCATCTGCTCAGGAGCTACंCGGAGCTGAGCCCGCGGCGGACTGCCCCAG TyrGluGlyThrSerGluI leGlnArgLeuValI leAlaGlyHisLeuLeuArgSerTyrArgSerEnd

GACTGCGGGAAGGCGCGGGÄGCCAGGGGCC̈TCCACCCCAACCCCGGCTCÄGAGACTGGGC̈GGCCCGGCGGGGGCTCCCTGGGGACCCCAG ATGGGCTCAGTGCTGCCACCCAGATCAGATCACATGGGAATGAGGCCCTCCCGACATTGG̈CAGCTCCGCCTCTGGGCCTTTCCGCCTCCT CACCACTGTGCCTCAAGTTCंCTCATCTAAGTGGCCCTGGCTCCTGGGGGCंGGGGTTGTGGGGGGGCTGAGCGACACTCAGGGACACCTCA GTTGTCCTCCंCGCGGGCCCTGGTGCCCTGǴCATGAAGGCCंCAGTGCGACAGGCCCTTGGTGGGGTCTGTCTTTTCCTTGAGGTCAGAGGT CAGGAGCAGG̈GCTGGGGTCAGGATGACGAGGCCTGGGGTCंCTGGTGTTGGGCAGGTGGTG்GGCTGGGCCATGGAGCTGGCCCAGAGGCC CCTCAGCCCTTTGTAAAGTCTGATGAAGGCAGGGTGGTGATTCATGCTGTGTGACTGACTGTGGGTAILAACACACCTGTCCCCCAAA

Figure 4. Nucleotide and deduced amino acid sequences of the human SCAD cDNAs. The positive numbering of amino acids and nucleotides starts at the first residue of the coding sequence. The region underlined with double lines matched the amino terminal sequences of the purified human and rat liver SCADs, and those underlined with a single line matched sequences derived from pure rat liver SCAD with an exception of three residues. The rat counterparts are shown under the discordant residues. Broken lines indicate equivocal amino acid assignments in peptide sequencing. The downward arrow between residues 24 and 25 indicates the cleavage site between the leader peptide and the mature protein. A possible polyadenylation signal in the $3^{\prime}$-untranslated region is boxed.

mology is $57.4 \%$. The longest stretch of consecutive identical residues was six, which was found near the carboxy-terminal region.

Dot matrix comparison of these two sequences was done with two different degrees of stringency as shown in Fig. 6. In general, a high degree of homology was again observed. At the low stringency (window, 30; stringency, 17), an initial blank and four major breaks are observed. When higher stringency was used, unevenness of homology can be seen: homology is generally higher in the carboxy-terminal half than in the aminoterminal half as shown in Fig. $6 B$.

Biosynthesis of variant $S C A D$ by cultured SCAD-deficient fibroblasts. When three SCAD-deficient cell lines were labeled with $\left[{ }^{35} \mathrm{~S}\right]$ methionine in the absence of rhodamine $6 \mathrm{G}$, a 41-kD band was detected from each of them. The 41-kD bands were identical in size to normal SCAD, and were immunoprecipitable (Fig. 7). The intensities of the radioactive SCAD bands in the three SCAD-deficient cell lines were comparable to that of the normal cell line, indicating that the amounts of variant SCAD protein synthesized in the deficient cell lines were similar to that in normal cell lines.

Blot hybridization analysis of RNAs from normal human and rat livers, and SCAD-deficient human fibroblasts. Northern blot hybridization analysis of total RNAs isolated from human and rat livers using the HS-1 cDNA insert as a probe revealed a single mRNA species with a size of $2.0 \mathrm{~kb}$ in both (Fig. $8 \mathrm{~A}$ ). When total RNA from two normal and three SCAD-deficient human fibroblasts were analyzed using the HS- 1 insert as a probe, a single mRNA band of $2.0 \mathrm{~kb}$ was detected in all of them (Fig. $8 \mathrm{~B}$ ). 
Table I. Amino Acid Composition of Human SCAD

\begin{tabular}{|c|c|c|}
\hline Amino acid & $\begin{array}{l}\text { Amino acid analysis } \\
\text { of purified protein }\end{array}$ & $\begin{array}{l}\text { Predicted from } \\
\text { cDNA sequence }\end{array}$ \\
\hline & \multicolumn{2}{|c|}{ number of residues per subunit } \\
\hline $\begin{array}{l}\text { Asp } \\
\text { Asn }\end{array}$ & 28 & 26 \\
\hline Thr & 22 & 22 \\
\hline Ser & 27 & 24 \\
\hline $\begin{array}{l}\text { Glu } \\
\text { Gln }\end{array}$ & 42 & 41 \\
\hline Pro & 15 & 15 \\
\hline Gly & 40 & 34 \\
\hline Ala & 52 & 54 \\
\hline Cys & 5 & 5 \\
\hline Val & 14 & 15 \\
\hline Met & 14 & 15 \\
\hline Ile & 23 & 26 \\
\hline Leu & 40 & 40 \\
\hline Tyr & 10 & 9 \\
\hline Phe & 12 & 13 \\
\hline His & 7 & 6 \\
\hline Lys & 21 & 22 \\
\hline Arg & 19 & 16 \\
\hline Trp & 2 & 5 \\
\hline
\end{tabular}

* Results derived from Finocchiaro et al. (5).

HSCAD 1 MAAA..... LLLARASGPARRALCPRAWRQLHTIYQ.SVELPETHQMLLQ 43

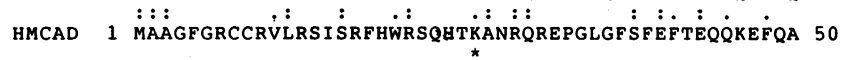
44 TCRDFAEKELLFPIAAQVDKEHLFPAAQVKKMGGLGLLAMDVPEELGGAGL 93 51 TARKFAREEII I PVAAEYDKTGEYPVPLIRRAWELGLMNTH I PENCGGLGL 100

94 DYLAYAIAMEEISRGCASTGVIMSVNNSLYLLGPILKFGSKEQKQAWVTPF 143 101 GTFDACLISEELAYGCTGVQTAIE.GNSLGQMPIIIAGNDQQKKKYLGRM 149 144 TSGDKIGCFALSEPGNGSDAGGASTTARAEGDSWVLNGTKAWI TNAWEAS 193

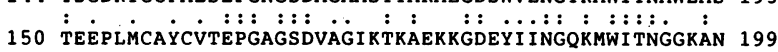
194 AAVVFASTD... . RALQNKGI SAFLVPMPTPGLTLGKKEDKLGIRGSSTAN 240 200 WYFLLARSDPDPKAPANKÄFTFFIVADTPGIQIGRKELNMGQRCSDTRG 249 241 LIFEDCRI PKDSILGEPGMG FKIAMQTLDMGRIGIASQALG IAQTALDCA 290 250 IVFEDVKVPKENVLIGDGAGFKVAMGAFDKTRPVVAAGAVGLAQRALDEA 299

291 VNYAENRMAFGAPLTKLQVIOFKLADMALALESARLLTWRAAMLKDNKKن 340 300 TKYALERKTFGKLLVEHQAISFMLAEMAMKVELARMSYQRAAWEVDSGRR 349 341 FIKEAAMAKLAASEAATAISHQAIQILGGMGYVTEMPAERHYRDARITEI 390 350 NTYYASI : : $:$ AKAFAGDIANQLATDAVQILGGNGFNEYPVEKLMRDAKIYQ 399

391 YEGTSEIQRLVIAGHLLRSYRS 412

400 YEGTSQIQRLIVAREHIDKYKN 421

Figure 5. Comparison of the amino acid sequence of human SCAD and human MCAD. Standard one-letter amino acid abbreviations are used. HSCAD and HMCAD represent the sequences of human SCAD and human MCAD, respectively. Gaps (.) were inserted to achieve maximum homology. Identical residues are indicated with double dots and conservative substitutions with a single dot. The conservative substitutions were identified by the BESTFIT program. Sequence data of human medium chain acyl-CoA dehydrogenase were taken from Kelly et al. (21).
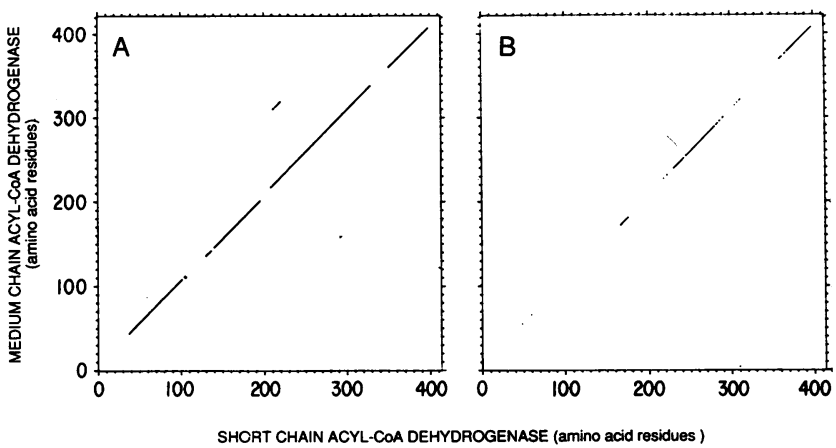

Figure 6. Dot matrix comparison of amino acid sequences of human SCAD and human MCAD. COMPARE program was used with window 30: $(A)$ with stringency 17 ; and $(B)$ with stringency 25 .

Analysis of restriction fragments in normal and SCAD-deficient cultured human skin fibroblasts. Genomic DNA from two normal and three SCAD-deficient fibroblast lines were digested with four restriction enzymes, and the fragments from each experiments were subjected to blot hybridization analysis using radioactive HS- 1 as a probe. In all the normal and SCAD-deficient cell lines, the sizes of the restriction fragments produced by these four enzymies were identical: digestion with TaqI or BamHI resulted in three bands each (Fig. 9, $A$ and $C$ ), whereas that with $\mathrm{HincII}$ (Fig. $9 \mathrm{~B}$ ) produced two fragments. Two bands, 8.5 and $10.0 \mathrm{~kb}$, were detected with EcoRI digestion (data not shown).

\section{Discussion}

The isolation of normal human SCAD cDNA clones and the determination of their sequences are the prerequisite for the study of the molecular basis of hereditary SCAD deficiency. It provides not only the normal human SCAD sequence as a data

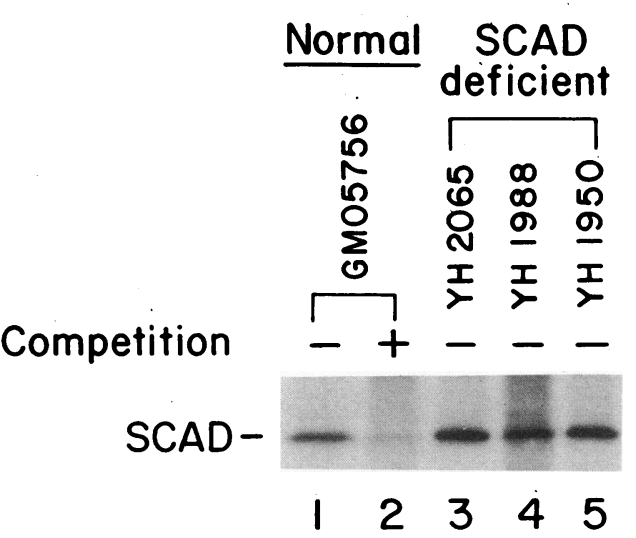

Figure 7. Electrophoretic analysis of variant SCAD synthesized in three SCAD-deficient cells and control. The experimental conditions were as described in Fig. 2. Lane 1, a normal fibroblast line immunoprecipitated without the addition of pure rat SCAD; lane 2, the same normal cell lines as in lane 1 , but immunoprecipitated after the addition of $7 \mu \mathrm{g}$ of pure rat SCAD (competition experiment). Lanes 3-5 each represent a SCAD-deficient cell line. Cell line numbers are presented at the top of each lane. 


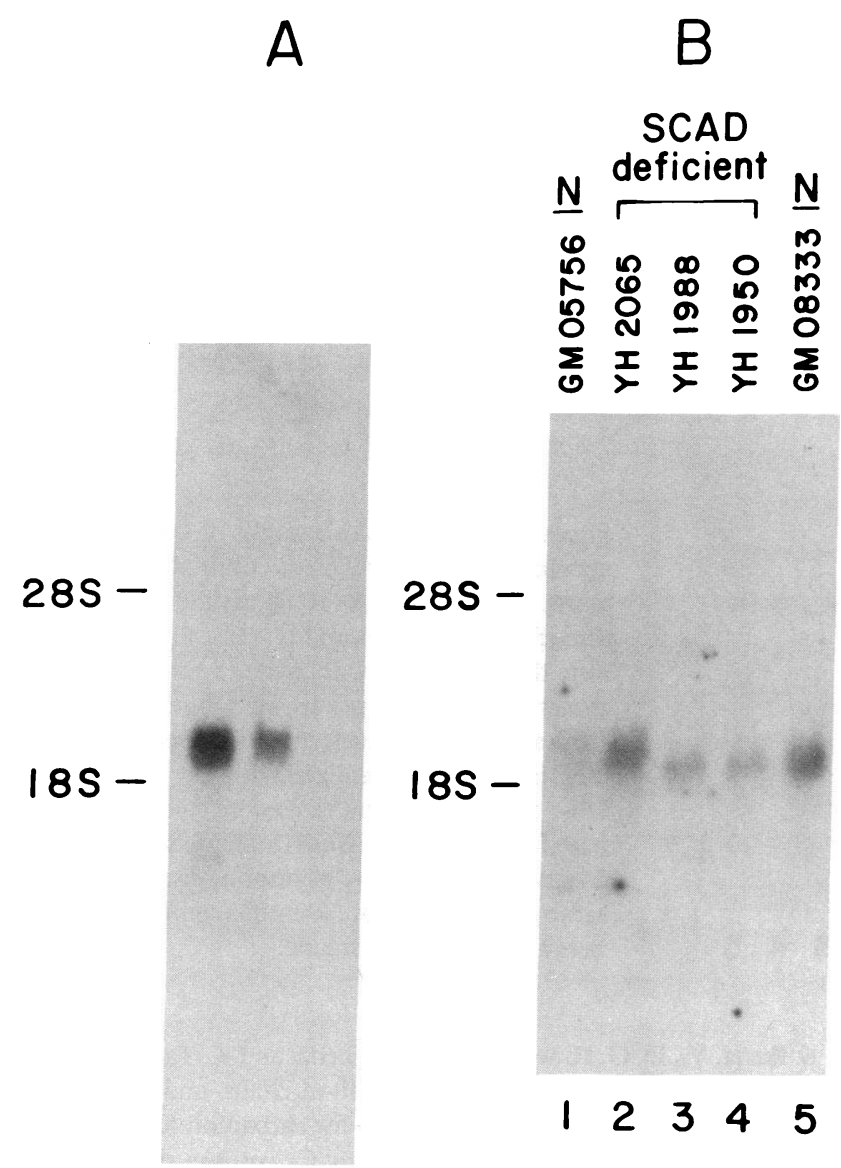

Figure 8. Northern blot analysis of normal and variant mRNAs. $(A)$ Analysis of RNA from normal human and rat livers: $20 \mu \mathrm{g}$ of total human or rat liver RNA was denatured and electrophoresed in a $1.0 \%$ agarose-formaldehyde gel. The RNA was transferred to Hybond-N membrane and hybridized with ${ }^{32}$ P-labeled HS-1 cDNA insert shown in Fig. 1. Lane 1, human liver RNA; lane 2, rat liver RNA; and lane 3, human poly(A)- RNA. (B) Analysis of variant mRNA in three SCAD-deficient cultured fibroblasts and normal controls. Total RNA ( $20 \mu \mathrm{g}$ each) from the three SCAD-deficient and two normal fibroblast lines was denatured by treatment with formamide and formaldehyde, and electrophoresed in a $1.0 \%$ agarose gel containing $2.2 \mathrm{M}$ formaldehyde. The RNA was transferred to $\mathrm{Hy}$ bond-N membrane and hybridized with the ${ }^{32} \mathrm{P}$-labeled HS-1 insert.

The cell lines are identified with the numbers at the top of each lane.

base to which the variant SCAD sequences can be compared, but also a probe for studying the structure of variant SCAD genes and their mRNAs. In this study, we first isolated a partial cDNA encoding rat SCAD, and we used the rat SCAD CDNA as probe to clone CDNAs encoding human SCAD. Authenticity of the resulting cDNA and deduced amino acid sequences as those of human SCAD was conclusively shown in this article by matching the deduced sequence to the amino terminal sequence of human SCAD and to the amino terminal and three tryptic peptide sequences of rat SCAD.

In the study of hereditary SCAD-deficient cell lines, we demonstrated study that variant SCAD protein was synthesized in these mutant cells in an amount comparable to normal cells. In all of the three cell lines, the size of the variant SCAD was indistinguishable from normal human SCAD as judged by their electrophoretic mobility. Thus, it is likely that the mutations in all of these mutant cells are point mutations. Consistent with this finding were the results from the blot hybridization analysis, which demonstrated that the size of SCAD mRNA in the three SCAD-deficient cell lines were identical to normal SCAD mRNA. In the Southern blot analysis, no restriction fragment length polymorphism (RFLP) was observed using TaqI, EcoRI, BamHI, and HincII in two normal and the three SCAD-deficient cell lines. No grossly visible deletions were seen with the SCAD-deficient cell lines.

Final identification of a point mutation must be established by sequence analysis of mutant cDNA and comparison to the normal SCAD cDNA. The preparation of mutant cDNA for this purpose has been greatly facilitated by the recent introduction of the polymerase chain reaction with the heat-stable Taq polymerase (23). The information provided by this study should allow application of this technique to and in the complete elucidation of the molecular basis of SCAD deficiency. If the point mutations in the three deficient cell lines are identical, then there is a possibility of developing a new useful clinical test based on the differential oligonucleotide hybridization. Alternatively, diagnosis by RFLP analysis is also possible. Currently, the biochemical diagnosis of SCAD deficiency has been difficult. In some SCAD-deficient patients, the amount of urinary ethylmalonic acid, considered to be specific for SCAD deficiency, is not particularly high, while its range in normal children varies considerably (24). Enzymatic assays of SCAD are time consuming and cumbersome, requiring ETF which must be purified from animal tissues (9), or prepared from large amounts of mitochondria from cultured skin fibroblasts (8). Also, because of overlap of the substrate specificities of SCAD and MCAD, the SCAD assay requires the addition of a monospecific antibody raised against MCAD to reliably eliminate MCAD activity. Therefore, a simpler alternative method for the diagnosis of SCAD deficiency is desired.

The elucidation of the primary structure of SCAD also provides important scientific knowledge with regard to the evolution and structure/function relationship of acyl-CoA dehydrogenases. We had previously hypothesized that the five acyl-CoA dehydrogenases belong to a gene family, the AcylCoA dehydrogenase family, based on the similarity of their catalytic mechanisms and physicochemical properties, such as molecular weight, subunit structure and prosthetic group (7). In this study, we have shown that human SCAD and MCAD share a high degree of homology. They share $36.7 \%$ of identical amino acid residues throughout their sequences, providing support at the molecular level for our hypothesis that five acyl-CoA dehydrogenases evolved from a common ancestral gene. However, this is in contrast to the $90.3 \%$ sequence similarity between human and rat SCAD (E. Naito and K. Tanaka, unpublished observation). The degree of sequence homology between SCAD and MCAD obviously is high enough to encode the structural and functional features commonly shared by various acyl-CoA dehydrogenases, yet heterologous enough to ensure their distinctive substrate specificity and immunogenicity. Cloning and sequencing of the three other acyl-CoA dehydrogenases would undoubtedly shed further light on the evolutionary relationship of the five acyl-CoA dehydrogenases. Analysis of these homologous sequences will also be crucial for the elucidation of the structural basis of their catalytic functions. 


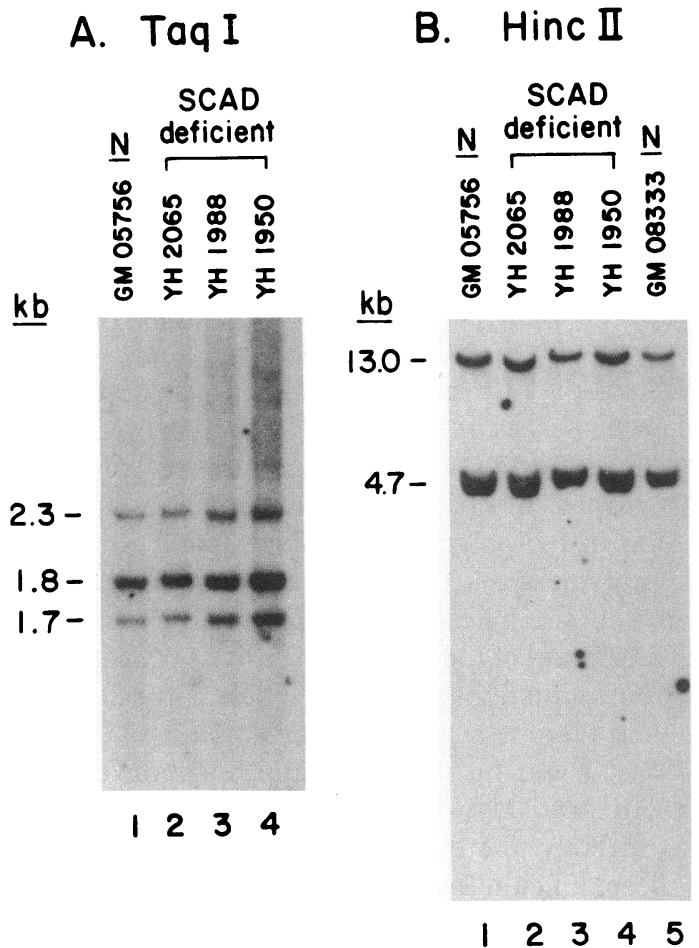

\section{Acknowledgments}

Human SCAD was purified by Dr. Gaetano Finocchiaro in our laboratory. Peptide sequencing was done by Dr. Ken Williams and Ms. Kathy Stone, Department of Molecular Biophysics and Biochemistry, Yale University School of Medicine. Amino-terminal sequence was determined by Dr. John Mole, University of Massachusetts School of Medicine, Worcester, MA. Cultured skin fibroblasts from three patients with hereditary SCAD deficiency were kindly provided by Drs. Carol Green, University of Colorado, Vivian E. Shih, Massachusetts General Hospital, and Susan Winters, Valley Children's Hospital, Fresno, CA. We thank Dr. Jerry Vockley and Ms. Connie Woznick for reading and preparing this manuscript, respectively.

This work was supported by grants from National Institutes of Health (DK-38154) and March of Dimes (1-378).

\section{References}

1. Ikeda, Y., K. Okamura-Ikeda, and K. Tanaka. 1985. Purification and characterization of short-chain, medium-chain, and longchain acyl-CoA dehydrogenases from rat liver mitochondria. J. Biol. Chem. 260:1311-1325.

2. Ikeda, Y., and K. Tanaka. 1983. Purification and characterization of isovaleryl coenzyme A dehydrogenase from rat liver mitochondria. J. Biol. Chem. 258:1077-1085.

3. Ikeda, Y., and K. Tanaka. 1983. Purification and characterization of 2-methyl-branched chain acyl coenzyme A dehydrogenase, an enzyme involved in the isoleucine and valine metabolism, from rat liver mitochondria. J. Biol. Chem. 258:9477-9487.

4. Ikeda, Y., S. M. Keese, W. A. Fenton, and K. Tanaka. 1987. Biosynthesis of four rat liver mitochondrial acyl-CoA dehydrogenases: in vitro synthesis, import into mitochondria, and processing of their precursors in a cell-free system and in cultured cells. Arch. Biochem. Biophys. 252:662-674.

5. Finocchiaro, G., M. Ito, and K. Tanaka. 1987. Purification and properties of short chain acyl-CoA, medium chain acyl-CoA, and isovaleryl-CoA dehydrogenases from human liver. J. Biol. Chem. 262:7982-7989.
6. Ikeda, Y., D. G. Hine, K. Okamura-Ikeda, and K. Tanaka. 1985 Mechanism of action of short-chain, medium-chain, and long-chain acyl-CoA dehydrogenase. Direct evidence for carbanion formation as an intermediate step using enzyme-catalyzed C-2 proton/deuteron exchange in the absence of C-3 exchange. J. Biol. Chem. 260:1326-1337.

7. Tanaka, K., Y. Ikeda, Y. Matsubara, and D. B. Hyman. 1987. Molecular basis of isovaleric acidemia and medium-chain acyl-CoA dehydrogenase deficiency. Enzyme (Basel). 38:91-107.

8. Amendt, B. A., C. Greene, L. Sweetman, J. Cloherty, V. Shih, A. Moon, L. Teel, and W. J. Rhead. 1987. Short-chain acyl-coenzyme A dehydrogenase deficiency. Clinical and biochemical studies in two patients. J. Clin. Invest. 79:1303-1309.

9. Coates, P. M., D. E. Hale, G. Finocchiaro, K. Tanaka, and S. C. Winter. 1988. Genetic deficiency of short-chain acyl-coenzyme A dehydrogenase in cultured fibroblasts from a patient with muscle carnitine deficiency and severe skeletal muscle weakness. J. Clin. Invest. 81:171-175.

10. Ikeda, Y., and K. Tanaka. 1987. Immunoprecipitation and electrophoretic analysis of four human acyl-CoA dehydrogenases and electron transfer flavoprotein using antibodies raised against the corresponding rat enzyme. Biochem. Med. Metab. Biol. 37:329-334.

11. Young, R. A., and R. W. Davis. 1983. Efficient isolation of genes by using antibody probes. Proc. Natl. Acad. Sci. USA. 80:11941198.

12. Maniatis, T., E. F. Fritsch, and J. Sambrook. 1982. Molecular Cloning: A Laboratory Manual. Cold Spring Harbor Laboratory, Cold Spring Harbor, NY. 1-545.

13. Feinberg, A. P., and B. Vogelstein. 1983. A technique for radiolabeling DNA restriction endonuclease fragments to high specific activity. Anal. Biochem. 132:6-13.

14. Sanger, F., S. Nicklen, and A. R. Coulson. 1977. DNA sequencing with chain-terminating inhibitors. Proc. Natl. Acad. Sci. USA. 74:5463-5467.

15. Ikeda, Y., S. M. Keese; and K. Tanaka. 1985. Molecular heterogeneity of variant isovaleryl-CoA dehydrogenase from cultured isovaleric acidemia fibroblasts. Proc. Natl. Acad. Sci. USA. 82:7081-7085.

16. Matsubara, Y., J. P. Kraus, T. L. Yang-Feng, U. Francke, L. E. Rosenberg, and K. Tanaka. 1986. Molecular cloning of cDNAs en- 
coding rat and human medium-chain acyl-CoA dehydrogenase and assignment of the gene to human chromosome 1. Proc. Natl. Acad. Sci. USA. 83:6543-6547.

17. Laemmli, U. K. 1970. Cleavage of structural proteins during the assembly of the head of bacteriophage T4. Nature (Lond.). 227:680-685.

18. Leonard, G. D., D. D. Mark, and F. B. James. 1986. Basic Method in Molecular Biology. Elsevier Science Publishing Co., New York. 130-135.

19. Hay, R., P. Boehni, and S. Gasser. 1984. How mitochondria import proteins. Biochim. Biophys. Acta. 779:65-87.

20. Nevins, J. R. 1983. The pathway of eukaryotic mRNA formation. Annu. Rev. Biochem. 52:441-466.

21. Kelly, D. P., J. J. Kim, J. J. Billadello, B. E. Hainline, T. W. Chu, and A. W. Strauss. 1987. Nucleotide sequence of medium-chain
acyl-CoA dehydrogenase mRNA and its expression in enzyme-deficient human tissue. Proc. Natl. Acad. Sci. USA. 84:4068-4072.

22. Matsubara, Y., J. P. Kraus, H. Ozasa, R. Glassberg, G. Finocchiaro, Y. Ikeda, J. Mole, L. E. Rosenberg, and K. Tanaka. 1987. Molecular cloning and nucleotide sequence of cDNA encoding the entire precursor of rat liver medium chain acyl coenzyme A dehydrogenase. J. Biol. Chem. 262:10104-10108.

23. Saiki, R. K., D. H. Gelfand, S. Stoffel, S. J. Scharf, R. Higuchi, G. T. Horn, K. B. Mullis, and H. A. Erlich. 1988. Primer-directed enzymatic amplification of DNA with a thermostable DNA polymerase. Science (Wash. DC). 239:487-491.

24. Duran, M., F. J. Walter, L. Bruinvis, and S. K. Wadman. 1983. The urinary excretion of ethylmalonic acid: what level requires further attention? Biochem. Med. 29:171-175. 